\title{
os Jacobinos Negros
}

Carlos Alexandre Barros Trubiliano ${ }^{1}$

(JAMES, C. L. R. Os jacobinos negros: Toussaint L'Ouverture e a revolução de São Domingos. São Paulo, Boitempo, 2010)

\section{SobreoSr. Cyril Lionel Robert Jamesz}

$\mathrm{O}$ historiador, romancista e jornalista Cyril Lionel Robert James nasceu em janeiro de 1901 na ilha de Trinidad. Teve uma infância e juventude privilegiada, marcada por uma excelente formação escolar e pela prática esportiva do cricket. Com apenas 19 anos deu início a sua carreira docente, lecionando literatura, na Royal Queen's College.

Em 1932, aos 31 anos, muda-se para a Grã-Bretanha, devido a sua paixão e conhecimento sobre cricket tornasse repórter esportivo do Manchester Guardian. Na terra da rainha, filia-se ao Partido Trabalhista Independente, (Independent Labour Party) e, em 1938, aderiu a IV Internacional Comunista, entrando em contato, mais intensamente, com as ideias de Leon Trotsky.

É notória a influência que as teses marxistas, em especial as interpretações trotskista, exercerão em suas obras "A Revolução Mundial 1917-1937", publicada em 1937, e os "Jacobinos negros" de 1938. Vale destacar, que nesse período, a Europa passava por grande instabilidade política, devido à ascensão do nazi-fascismo e pelo totalitarismo stalinista na URSS.

\footnotetext{
${ }^{1}$ Doutorando em História Política da Universidade Julho de Mesquita (Unesp - Campus Franca)/ Bolsista FAPESP. trubiliano@hotmail.com

${ }^{2}$ Informações extraídas da comunicação feita pelo doutorando, Unesp/Franca, Rubens Arantes no curso "A escravidão na cultura ocidental"; e pela comunicação de: SILVA, Tiago Hilarino Christophe da. Um marxista caribenho: o pensamento e a práxis de Cyril Lionel Robert James. Texto integrante dos Anais do XIX Encontro Regional de História: Poder, Violência e Exclusão. ANPUH/SP-USP. São Paulo, 08 a 12 de setembro de 2008. Cd-Rom.
} 
Por conta da Segunda Guerra Mundial, James refugia-se nos Estados Unidos, onde deu prosseguimento a suas atividades acadêmicas e políticas. Membro fundador do Partido Socialista dos Trabalhadores (Socialist Workers Party ou SWP) publicou em 1948 o manifesto "Uma resposta revolucionária ao problema do negro nos Estados Unidos”.

Devido a sua militância, em 1953, James foi expulso dos Estados Unidos. Ele decidiu voltar à Inglaterra, onde permaneceu até 1958, quando, então, retorna a Trinidad. Em sua terra natal, envolve-se na luta pela libertação anti-colonialista britânica. Ainda na década de 1950 publica a obra "Navegantes, Renegados e Náufragos: Herman Melville e o mundo em que vivemos” em 1953.

A década de 1960 foi bem movimentada para o nosso autor, no campo político James se envolve nos movimentos de independência na África e em Trinidad, é entusiasta dos ideais do Pan-Africanismo e da integração das ilhas caribenhas em uma - Federação das Índias Ocidentais.

No tocante a carreira acadêmica e produção intelectual publica em 1960, "Politica Moderna", em 1962, "Partidos Politicos Livres nas Índias Ocidentais" e, em 1963, “Além da Fronteira”. Em 1968, vem o convite para lecionar na prestigiada Universidade de Columbia nos Estados Unidos.

Durante a década de 1970, James retorna para a Inglaterra e ainda encontra fôlego para publicar "Nkruma e a Revolução de Gana" em 1977. Na década de 1980 retorna para Trinidad aonde veio a falecer em 1989, deixando como legado, uma produção acadêmica respeitada e de referência para estudos nas ciências humanas, bem com, um exemplo de vida marcado pela entrega a militância e a seus ideais.

\section{Sobre a obra: os jacobinos negros: Tous- saint L'ouverture e a revolução de São Do- mingos}

Em 1938 James, residindo em Londres, publica "Os jacobinos negros" (The black jacobins), a obra trás questões referentes à revolução negra de São Domingos e a sua relação com a sua principal liderança: Toussaint L'Ouverture. 
No Brasil o texto terá sua primeira tradução apenas em 2000, feita por Afonso Teixeira Filho, com uma edição revisada em 2007 pela Editora Boitempo. Em suas 400 páginas a estrutura física do livro está dividida em 13 capítulos acompanhados de um apêndice intitulado "De Toussaint L'Ouverture a Fidel Castro".

Para maior compreensão do livro, temos que levar em conta o contexto em que foi escrito: descrédito do liberalismo, auge do nazi-fascismo e predominância das teorias eugênicas. Tal cenário acabou motivando o autor a escrever um texto, que denunciava o estado de opressão em que vivam os africanos e seus descendentes, seja na África ou em outras partes do globo, tornando a posteriori leitura obrigatória para estudos sobre a diáspora Africana.

Embora o ano de publicação date de 1938 James já havia escrito sobre o assunto antes, em 1932. O trabalho de levantamento bibliográfico e de fontes foi grandioso, sendo necessário até "importar da França livros que trataram seriamente desses eventos tão célebres na história daquele país. "3. A pesquisa também contou com correspondências e relatórios oficiais, compêndios de história do comercio colonial, narrativas de viajantes, dados estatísticos e biografias.

Ainda no tocante a função social da obra e sua importância para a interpretação histórica, James nos aponta, que a grande virtude contida no "Os jacobinos negros" é a ênfase dada ao protagonismo dos escravos no processo revolucionário, nas palavras do autor: "foram os próprios escravos que fizeram a revolução." 4 , tendo especial destaque a figura do líder do movimento - "foi quase totalmente trabalho de um único homem: Toussaint L'Ouverture" ${ }^{5}$.

\section{A tese central}

A viabilização da revolução no Haiti deve-se, em parte, ao fato dos escravos já se encontrarem, em certa mediada, organizados e disciplinados, devido o sistema fabril, já implantada, no século XVIII, nas lavouras da ilha. Para o autor:

Trabalhando e vivendo juntos em grupos de centenas nos enormes engenhos de açúcar que cobriam a Planície do Norte, eles estavam mais próximos de um proletariado moderno do que qualquer outro grupo de trabalhadores

\footnotetext{
${ }^{3}$ JAMES, C. L. R. Op. cit., p. 11.

${ }^{4}$ Idem, p. 14.

${ }^{5}$ Idem, p. 15.
} 
daquela época, e o levante foi, por essa razão, um movimento de massas inteiramente preparado e organizado ${ }^{6}$. (Grifo nosso)

Observa-se que para o autor, já no século XVIII, havia entre os escravos do Haiti uma consciência de classe, que os permitiu se organizarem para combater a exploração colonial. Deve-se destacar também, que os revoltosos tinham o desejo de libertar-se da tirania a que eram submetidos, deste modo, se insurgiam contra os maus tratos, ainda nos navios negreiros - "Morriam não apenas por causa do tratamento, mas também de mágoa, de raiva e de desespero. Faziam longas greves de fome; desatavam as suas cadeias e se atiravam sobre a tripulação numa tentativa inútil de revolta."

\section{Leitura Marxista}

\section{Revolta escrava ou uma luta declasses?}

Mesmo para os leitores que não tem contato com a biografia de James, a terminologia empregada por ele, deixa claro que se trata de uma leitura fundada no marxismo. Não são poucos os conceitos empregos em seu texto: proletariado, imperialismo, luta de classes, revolta das massas trabalhadoras, exploração dos escravos, dos trabalhadores - constituem a interpretação dado pelo nosso autor para o problema em que se dispões a analisar além das citações a Lênin e a Trotsky.

É possível afirmarmos, diante do seu livro, bem como de sua biografia, que James, como filiado ao Partido Trabalhista Independente, militante da IV Internacional, fundador do Partido Socialista dos Trabalhadores (SWP) e integrante ativo de diversos movimentos sociais, de que demarcou sua interpretação sobre a História a partir de sua leitura da "teoria da revolução permanente" proposta por Leon Trotsky.

Respondendo a questão feita acima, se partirmos da leitura de nosso autor sobre o fato histórico que ocorreu no Haiti, foi à demonstração de uma luta de

\footnotetext{
${ }^{6}$ Idem, p. 99.

${ }^{7}$ Idem, p. 23.
} 
classes. Tal leitura recebeu diversa criticas, uma das mais conhecidas no Brasil foi feita pelo professor Dr. Jacob Gorender

As rebeliões, no começo do século XIX, no continente americano, só podiam ter caráter antiescravista e anticolonialista. No mundo atual, o cenário internacional é sacudido pelas lutas anticapitalistas e antiimperialistas. Trata-se de etapas históricas profundamente diversas. Não obstante, o anacronismo não prejudica o texto que se segue ao Preâmbulo. ${ }^{8}$

Não podemos deixar de mencionar a crítica feita pelo professor Jacob Gorender ao preâmbulo datado de 1980, em que James liga as rebeliões escravas no Haiti com as lutas operárias do século XX cometendo aquele que é considerado o maior dos pecados para o historiador: o Anacronismo. Todavia dentro de uma abordagem histórica e social, entendemos que devemos contextualizar o autor e sua obra com sua leitura de vida, nos parece que a escrita de "Os jacobinos negros" e o prefácio de 1980, antes de um texto acadêmico é um esforço militante, que tem como pretensão denunciar, conforme o próprio autor, a "perseguição $e$ opressão" que vivem os africanos e os afro-descendentes.

\section{O caso Haiti}

Em 1789, a colônia francesa das Índias Ocidentais de São Domingos representava dois terços do comércio exterior da França e era o maior mercado individual para o tráfico negreiro europeu. Era parte integral da vida econômica da época, a maior colônia do mundo, o orgulho da França e a inveja de todas as outras nações imperialistas. A sua estrutura era sustentada pelo trabalho de meio milhão de escravos. ${ }^{9}$

Basta ligar a televisão, sintonizar o radio ou acessar a internet e entrar em contato com as notícias que vem do Haiti. Logo nos depararmos com as palavras: tragédia, caos, crise, fome, morte, doenças. Estas informações quando soam aos nossos ouvidos nos faz refletir - como uma colônia produtora de açúcar, café, anil, cacau, algodão, entre outros produtos, responsável por dois terços do co-

${ }^{8}$ GORENDER, Jacob. O épico e o trágico na história Haiti. Estudos Avançados. V. 18, n. 50, 2004, p. 296.

${ }^{9}$ JAMES, C. L. R. Op. cit., p. 15. 
mércio exterior da França, que em 1789, exportou 11 milhões de libras ${ }^{10}$, fracassou no projeto de Estado-nação livre da miséria e das desigualdades? James propôs uma resposta.

Para o nosso autor, o fracasso do projeto Haiti não se deve apenas a falta de diversidade econômica, uma vez que, a produção primária dominava a paisagem, não havendo maiores perspectivas de geração de riqueza, em especial ao desenvolvimento industrial.

$\mathrm{Na}$ análise de James o isolamento ou quarentena imposta pelas potências imperialistas e até mesmo as nações latino-americanas, foram responsáveis pelo atrofiamento econômico da ilha caribenha, não permitindo o desenvolvimento de uma economia mais sólida, tendo por consequência o agravamento das desigualdades históricas já bem conhecidas pela massa trabalhadora do Haiti.

\section{$v$. Considerações finais}

Compreendemos o texto de Cyril Lionel Robert James, como sendo um esforço para responder questões que não se restringem somente ao caso da independência do Haiti, mas como uma leitura sobre a exploração do trabalho escravo e as formas de relação do sistema escravista e colonial na América.

Para finalizarmos, podemos dizer que ainda hoje, o texto serve como instrumento de análise para entendermos as relações de trabalho em muitos países latino-americanos, onde encontramos cada vez mais latente essa realidade apregoada pelo método capitalista de exploração, proposta pela manutenção dos grandes latifúndios, das monoculturas de exportação e da exploração da mão de obra dos trabalhadores do campo.

10 Idem. 